University of Wollongong

Research Online

Australian Institute for Innovative Materials -

Papers

Australian Institute for Innovative Materials

$1-1-2015$

Improvement in structure and superconductivity of bulk FeSe0.5Te0.5

superconductors by optimizing sintering temperature

Ning Chen

Tianjin University

Yongchang Liu

Tianjin University

Zongqing $\mathrm{Ma}$

University of Wollongong, zqma@uow.edu.au

Liming Yu

Tianjin University

Huijun Li

Tianjin University

Follow this and additional works at: https://ro.uow.edu.au/aiimpapers

Part of the Engineering Commons, and the Physical Sciences and Mathematics Commons

Research Online is the open access institutional repository for the University of Wollongong. For further information contact the UOW Library: research-pubs@uow.edu.au 


\title{
Improvement in structure and superconductivity of bulk FeSe0.5Te0.5 superconductors by optimizing sintering temperature
}

\begin{abstract}
Sintering temperature plays a vital role in the evolution of phase structure and microstructure in polycrystalline FeSe0.5Te0.5 bulks fabricated by the two-step sintering method, and thus significantly influences their superconducting properties. Elevated sintering temperature $\left(600-700^{\circ} \mathrm{C}\right)$ at second step facilitates the substitution of Te into the superconducting phase, which leads to the increased lattice distortion and thus contributes to the enhancement of superconductivity (the value of Tc reaches 15.6K). At the same time, the accelerated growth of the superconducting grains and the improved homogeneity motivated by elevated sintering temperature serve as the main reason for the sharp superconducting transition.
\end{abstract}

\section{Keywords}

5 te0, fese0, bulk, superconductivity, structure, temperature, improvement, sintering, optimizing, superconductors, 5

Disciplines

Engineering | Physical Sciences and Mathematics

\section{Publication Details}

Chen, N., Liu, Y., Ma, Z., Yu, L. \& Li, H. (2015). Improvement in structure and superconductivity of bulk FeSe0.5Te0.5 superconductors by optimizing sintering temperature. Scripta Materialia, 112 152-155. 
ARTICLE

\section{Uniform yolk-shell iron sulfide-carbon nanospheres for superior sodium-iron sulfide batteries}

Yun-Xiao Wang ${ }^{1,2, \star}$, Jianping Yang ${ }^{1,2,3, \star}$, Shu-Lei Chou1, Hua Kun Liu1, Wei-xian Zhang ${ }^{3}$, Dongyuan $Z_{\text {hao }}^{2} \&$ Shi Xue Dou ${ }^{1}$

Sodium-metal sulfide battery holds great promise for sustainable and cost-effective applications. Nevertheless, achieving high capacity and cycling stability remains a great challenge. Here, uniform yolk-shell iron sulfide-carbon nanospheres have been synthesized as cathode materials for the emerging sodium sulfide battery to achieve remarkable capacity of $\sim 545 \mathrm{~mA} \mathrm{~h}^{-1}$ over 100 cycles at $0.2 \mathrm{C}\left(100 \mathrm{~mA} \mathrm{~g}^{-1}\right)$, delivering ultrahigh energy density of $\sim 438 \mathrm{Wh} \mathrm{kg}^{-1}$. The proven conversion reaction between sodium and iron sulfide results in high capacity but severe volume changes. Nanostructural design, including of nanosized iron sulfide yolks $(\sim 170 \mathrm{~nm})$ with porous carbon shells $(\sim 30 \mathrm{~nm})$ and extra void space $(\sim 20 \mathrm{~nm})$ in between, has been used to achieve excellent cycling performance without sacrificing capacity. This sustainable sodium-iron sulfide battery is a promising candidate for stationary energy storage. Furthermore, this spatially confined sulfuration strategy offers a general method for other yolk-shell metal sulfide-carbon composites.

\footnotetext{
${ }^{1}$ Institute for Superconducting and Electronic Materials, Australian Institute of Innovative Materials, University of Wollongong, Innovation Campus, Squires Way, North Wollongong, New South Wales 2500, Australia. ${ }^{2}$ Laboratory of Advanced Materials, Shanghai Key Laboratory of Molecular Catalysis, Department of Chemistry, iChEM, Fudan University, Shanghai 200433, China. ${ }^{3}$ State Key Laboratory of Pollution Control and Resources Reuse, College of Environmental Science and Engineering, Tongji University, Shanghai 200092, China. ${ }^{\star}$ These authors contributed equally to this work. Correspondence and requests for materials should be addressed to S.L.C. (email: shulei@uow.edu.au) or to D.Y.Z. (email: dyzhao@fudan.edu.cn).
} 
O wing to the increased demand for energy and the need to reduce carbon emissions, energy storage innovation has been a constant global concern over the past decade. Electric vehicles (EVs) and plug-in hybrid EVs are emerging, to reduce our energy dependence on fossil fuels for transportation systems in the future. Lithium-ion batteries (LIBs) have successfully been applied in EV and plug-in hybrid EV trials. Nevertheless, it should be pointed out that concerns about LIBs have arisen both in terms of the high cost and the limitations of lithium resources ${ }^{1,2}$. Therefore, research on sodium-based technologies, including Na-ion batteries (NIBs), roomtemperature sodium-sulfur batteries (RT-Na/S), and novel Na$\mathrm{O}_{2}$ batteries, has gained momentum due to the overwhelming advantages with regards to the low cost and abundance of sodium resources $^{3-5}$. For NIBs, there is still a long way to go to achieve a sodium-ion full cell system with satisfying energy density and cycling life, as the current research on NIBs has been mainly focused on the search for suitable cathodes ${ }^{6-14}$ and anodes ${ }^{15-19}$. For $\mathrm{Na}-\mathrm{O}_{2}$ batteries, the exploration is only in its initial stage ${ }^{20,21}$. Among these sodium-based energy storage systems, the RT-Na/S battery is predicted to deliver high energy density (theoretical value: $760 \mathrm{Wh} \mathrm{kg}^{-1}$ ). Compared with the $\mathrm{Li} / \mathrm{S}$ battery, however, operation of the $\mathrm{Na} / \mathrm{S}$ battery at ambient temperature faces a greater critical challenge, because the shuttle effect of sodium polysulfides is much exacerbated, leading to low efficiency and rapid capacity decay on cycling ${ }^{22}$. Even though essential progress has been achieved on the ambient $\mathrm{Na} / \mathrm{S}$ battery ${ }^{23-24}$, the best result can merely reach the energy density of $191 \mathrm{Wh} \mathrm{kg}^{-1}$ over 200 cycles. Thus, innovation leading to sodium-based technologies with high energy and power densities is urgently needed.

On the other hand, the emerging sodium-metal sulfide battery has drawn extensive attention owing to its high energy and power densities; the typical cathodes includes iron sulfide (FeS) (ref. 25), $\mathrm{FeS}_{2}$ (refs 26,27), $\mathrm{SnS}_{2}$ (ref. 28), $\mathrm{MoS}_{2}$ (ref. 29), $\mathrm{Ni}_{3} \mathrm{~S}_{2}$ (ref. 30), $\mathrm{CuS}$ (ref. 31) and $\mathrm{Sb}_{2} \mathrm{~S}_{3}$ (ref. 32). Among all the reported metal sulfides, FeS has risen to prominence, owing to its high theoretical capacity $\left(\sim 610 \mathrm{mAh}^{-1}\right)$, high voltage plateau, cost effectiveness, environmental benignity and abundance in nature. The $\mathrm{Na} / \mathrm{FeS}$ battery, however, shows inferior electrochemical properties due to the detrimental challenges of low conductivity, sluggish kinetics and severe volume changes in the FeS cathode during sodiation/desodiation processes ${ }^{25}$. It is obvious that achieving high capacity is essential and imperative for practical application of the $\mathrm{Na} / \mathrm{FeS}$ battery. To solve these problems, we designed yolk-shell FeS@carbon nanospheres (FeS@C) as cathode materials. First, the porous carbon shells could enhance conductivity of the active materials, leading to a high reversible capacity. Second, the nanosized FeS cores can offer large electrode/electrolyte contact areas and short diffusion paths for electron and ions, which are favourable to improve the sodium reaction rate, alleviating structural degradation and shortening $\mathrm{Na}^{+}$diffusion paths. More importantly, the suitable void space is able to buffer the large volume variations of FeS during sodiation/ desodiation processes, which could maintain the original nanoparticle morphology of the FeS@C and gain prolonged cycling stability ${ }^{33}$. To the best of our knowledge, however, no yolk-shell FeS@C structure has been studied as yet due to the challenges of its synthesis.

Herein we have successfully explored a spatially confined sulfuration strategy for the preparation of uniform FeS@C yolkshell spheres. Unique FeS@C yolk-shell nanospheres have been configured for the very first time, which consist of single crystalline FeS yolks with an average size of $\sim 170 \mathrm{~nm}$, specially fabricated void spaces of $\sim 20 \mathrm{~nm}$ and porous carbon shells with a thickness of $\sim 30 \mathrm{~nm}$. Owing to the multifunctionality of the
FeS@C structure, the Na/FeS@C battery is capable of reaching the high capacity of $\sim 545 \mathrm{~mA} \mathrm{~h}^{-1}$ over 100 cycles. Furthermore, the remarkable energy density $\left(\sim 438 \mathrm{Wh} \mathrm{kg}^{-1}\right)$ and excellent rate capability $\left(\sim 452 \mathrm{~mA} \mathrm{~h}^{-1}\right.$ at $\left.5 \mathrm{C}\right)$ ensure its great promise for commercial utilization. In addition, the involved Na-storage mechanism has been derived for comprehensive understanding of this promising $\mathrm{Na} / \mathrm{FeS}$ system.

\section{Results}

Material synthesis and characterization. The synthetic procedures for the uniform yolk-shell structured FeS@C nanospheres through a spatially confined sulfuration strategy are illustrated in Fig. 1. First, uniform $\mathrm{Fe}_{3} \mathrm{O}_{4}$ nanoparticles are synthesized, with each of the $\mathrm{Fe}_{3} \mathrm{O}_{4}$ nanoparticles assembled from a number of magnetite nanocrystals, thereby leading to abundant nanopores from the packing. Second, a sacrificial layer of condensed silica coated on the $\mathrm{Fe}_{3} \mathrm{O}_{4}$ nanoparticles via the conventional Stöber method, followed by coating with a polymeric layer of resorcinol formaldehyde (RF) via a sol-gel process. Third, uniform $\mathrm{Fe}_{3} \mathrm{O}_{4} @ \mathrm{C}$ nanospheres with fine yolk-shell structures are obtained through a carbonization process, followed by etching away the sacrificial silica layer with sodium hydroxide $(\mathrm{NaOH})$ solution. Then, there is a crucial step, where sulfur reactant is impregnated into the void spaces of the $\mathrm{Fe}_{3} \mathrm{O}_{4} @ \mathrm{C}$ nanospheres by the melt-diffusion approach and $\mathrm{Fe}_{3} \mathrm{O}_{4}$-S@C mixture nanospheres are constructed. Finally, the uniform yolk-shell FeS@C nanospheres are fabricated via the spatially confined sulfuration strategy based on the sealed solid reaction of $\mathrm{Fe}_{3} \mathrm{O}_{4}$ and the loaded sulfur in the former void space. The elaborate yolk-shell structure of the uniform $\mathrm{Fe}_{3} \mathrm{O}_{4} @ \mathrm{C}$ nanospheres plays a vital role in this strategy. As shown in the transmission electron microscope (TEM) image (Fig. 1), the nanopores (rough size of $\sim 5 \mathrm{~nm}$ ) in each $\mathrm{Fe}_{3} \mathrm{O}_{4}$ core with an average diameter of $\sim 180 \mathrm{~nm}$ are beneficial for sufficient sulfur penetration and absorption, to make sure that the formation of FeS particles takes place inside of each carbon shell. Moreover, the void space $(\sim 20 \mathrm{~nm})$ derived from the etching of the silica middle layer also provides sufficient room for sulfur impregnation (Supplementary Fig. 1a,b). On the other hand, the carbon shells $(\sim 30 \mathrm{~nm})$ can confine the reaction zone of the $\mathrm{Fe}_{3} \mathrm{O}_{4}$ and $\mathrm{S}$, and avoid the further growth of the FeS nanoparticles to micron size. Meanwhile, the carbon shells are proven to be porous by nitrogen sorption analysis (Supplementary Fig. 1c,d), which facilitates the penetration of sulfur by the simple meltdiffusion method ${ }^{34,35}$. The success of this strategy could be

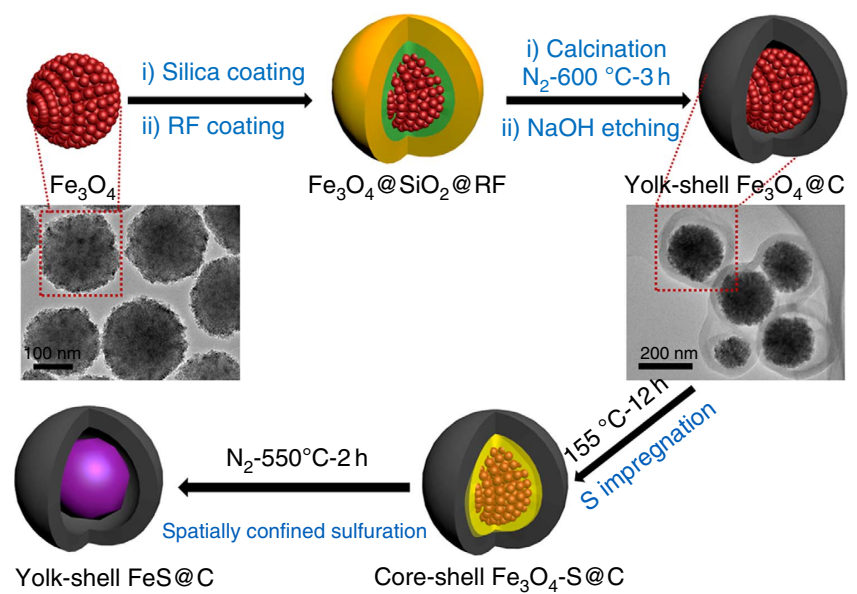

Figure 1 | Schematic illustration of the synthesis of yolk-shell FeS@C. TEM images of the $\mathrm{Fe}_{3} \mathrm{O}_{4}$ nanospheres and yolk-shell structured $\mathrm{Fe}_{3} \mathrm{O}_{4} @ \mathrm{C}$ nanospheres have also been inserted in the corresponding positions. 
confirmed by the TEM images and the corresponding phase mapping of the $\mathrm{Fe}_{3} \mathrm{O}_{4}$-S@C mixture nanospheres (Supplementary Fig. 2), where the void space is fully filled in by the impregnated solid sulfur, leading to the coexistence of the two phases of $\mathrm{Fe}_{3} \mathrm{O}_{4}$ and $\mathrm{S}$ in the carbon shells. For comparison, micron-sized $\mathrm{FeS}$ (micro-FeS) particles and core-shell $\mathrm{FeS} / \mathrm{C}$ nanoparticles were obtained by direct solid reaction of $\mathrm{Fe}_{3} \mathrm{O}_{4}$ nanoparticles and of core-shell $\mathrm{Fe}_{3} \mathrm{O}_{4} / \mathrm{C}$ nanoparticles with impregnated sulfur, respectively (Supplementary Figs 3 and 4). Assuming the formation of $\mathrm{Fe}_{2} \mathrm{O}_{3}, \mathrm{SO}_{2}$ and $\mathrm{CO}_{2}$ in air atmosphere at $900^{\circ} \mathrm{C}$, the carbon contents of the core-shell $\mathrm{FeS} / \mathrm{C}$ and the yolk-shell FeS@C are estimated to be $13 \%$ and 17\%, respectively, according to the thermogravimetric analysis results (Supplementary Fig. 5).

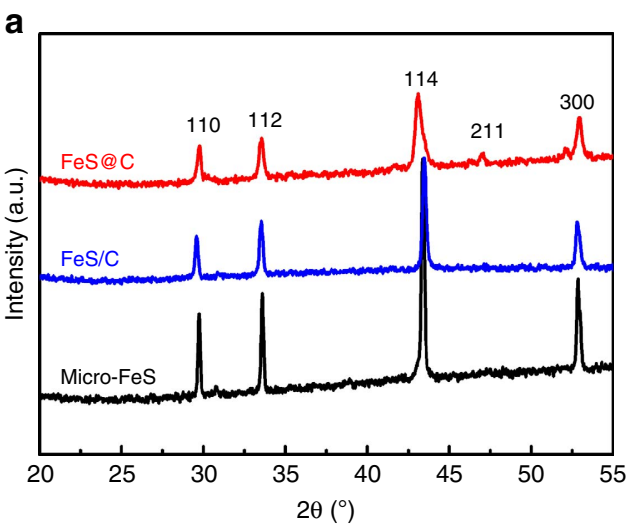

b
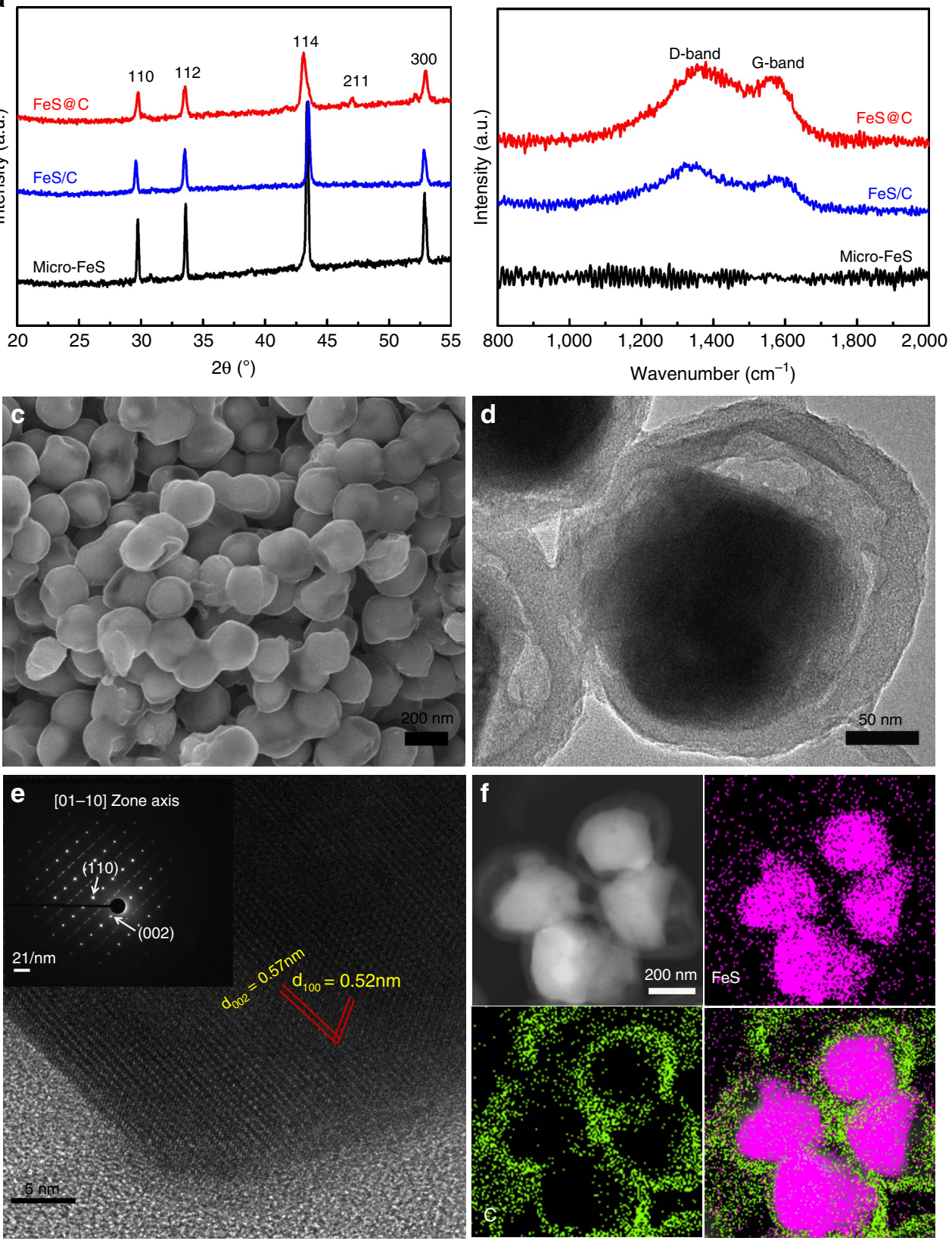

Figure 2 | Physical characterization of the three samples. (a) XRD patterns and (b) Raman spectra of the micro-FeS, core-shell FeS/C nanospheres and yolk-shell FeS@C nanospheres. (c) SEM, (d) TEM and (e) high-resolution TEM images with the corresponding SAED pattern (inset) and (f) scanning TEM (STEM) image with phase mapping for the yolk-shell FeS@C nanospheres.
As depicted in Fig. 2a, all X-ray diffraction (XRD) peaks of the micro-FeS, core-shell FeS/C and uniform yolk-shell FeS@C nanospheres can be indexed to troilite crystalline $\mathrm{FeS}$ with lattice constants $a=5.958 \AA, c=11.740 \AA$ (JCPDF no. 00-037-0477) without impurity, demonstrating that the $\mathrm{Fe}_{3} \mathrm{O}_{4}$ nanoparticles have been successfully reacted with impregnated sulfur to form pure-phase FeS crystals. In contrast, the diffraction peaks of the yolk-shell composites are lower in intensity and more broadened, which indicates the smaller crystalline size of the FeS. No obvious diffraction peak from carbon can be detected, which is ascribed to the amorphous nature of the carbon shells. As further confirmed by the Raman spectra (Fig. 2b), two peaks centred at 1,334 and $1,589 \mathrm{~cm}^{-1}$ can be observed for the core-shell $\mathrm{FeS} / \mathrm{C}$ and the uniform yolk-shell FeS@C nanospheres, corresponding to the 
characteristic disorder-induced D-band and the graphitic G-band of carbon, respectively. Furthermore, the strong intensity of the D-band indicates that the carbon shells are amorphous. The scanning electron microscope (SEM) image in Fig. 2c shows the high quality of the homogeneous and uniform yolk-shell FeS@C nanospheres. The electron beam could penetrate through the carbon shells, confirming the yolk-shell structure of FeS@C with a particle size of $\sim 260 \mathrm{~nm}$ (outside diameter). It is notable that the FeS@C spheres generally inherit the yolk-shell morphology and diameter of the $\mathrm{Fe}_{3} \mathrm{O}_{4} @ \mathrm{C}$ (Supplementary Fig. 1).The TEM images further reveal that the FeS yolks $\sim 170 \mathrm{~nm}$ in diameter are crystalline single particle and homogeneously encapsulated by the carbon shells $(\sim 30 \mathrm{~nm})$ with void space $\sim 20 \mathrm{~nm}$ in thickness in between (Fig. 2d). Furthermore, the selected area electron diffraction (SAED) pattern in the inset of Fig. 2e displays a set of parallel fringes with $d$-spacing of 0.52 and $0.57 \mathrm{~nm}$, respectively, corresponding to the (100) and (002) planes of single crystalline FeS. The SAED pattern can be indexed as the single-crystal troilite $\mathrm{FeS}$ structure with the incident electron beam parallel to the $01-10$ orientation as well. Moreover, the phase mapping of the yolk-shell FeS@C nanospheres in Fig. 2f demonstrates that the $\mathrm{FeS}$ yolks and the void space results from the interior reaction of $\mathrm{Fe}_{3} \mathrm{O}_{4}$ and $\mathrm{S}$ in the core-shell $\mathrm{Fe}_{3} \mathrm{O}_{4}-\mathrm{S} @ \mathrm{C}$ mixture (Supplementary Fig. 2). All these results verify that purephase FeS encapsulated by porous carbon in a yolk-shell nanosphere has been successfully fabricated via the spatially confined sulfuration strategy.

Sodium-storage mechanism. Charge and discharge curves, exsitu XRD and ex-situ X-ray photoelectron spectroscopy (XPS) were used to investigate the sodium-storage mechanism of the crystalline FeS particles. The charge and discharge curves of the micro-FeS-based battery at a current density of $50 \mathrm{mAg}^{-1}$ are displayed in Fig. 3a. A distinct plateau occurs at $\sim 0.85 \mathrm{~V}$ for the first discharge process, which is supposed to originate from reactions between $\mathrm{FeS}$ and $\mathrm{Na}$, with the formation of $\mathrm{Fe}, \mathrm{Na}_{2} \mathrm{~S}$ and Na-rich phases corresponding to the quantity of sodiation per FeS (ref. 36). When the cell is discharged to $0.01 \mathrm{~V}$, a further sodiation reaction takes place to form $\mathrm{Na}_{2} \mathrm{~S}$ and $\mathrm{Fe}$ along with the formation of a solid electrolyte interphase (SEI) film ${ }^{37}$. More evidence is revealed via ex-situ XRD at selected typical states: fresh electrode, the first discharge to $0.01 \mathrm{~V}(\mathrm{D} 0.01 \mathrm{~V})$ and the first charge to $2.3 \mathrm{~V}(\mathrm{C} 2.3 \mathrm{~V})$. The XRD patterns were collected with a scan rate of 0.5 degree per minute from the powders scraped off the electrodes at the selected states. For the XRD
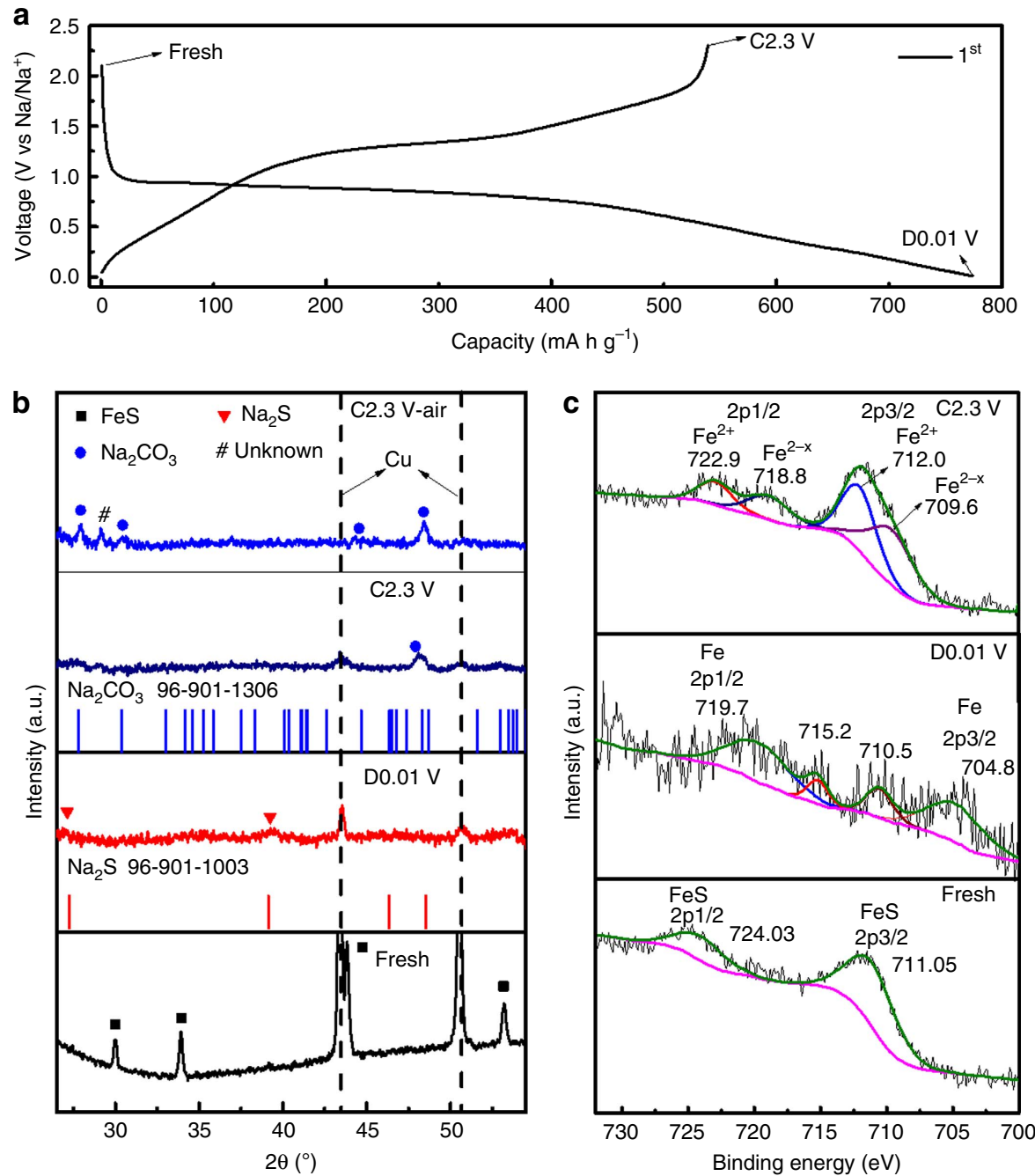

Figure 3 | Sodium-storage mechanism of $\mathbf{N a / F e S}$ battery. (a) Charge/discharge profiles of the micro-FeS electrode for the first cycle at $50 \mathrm{mAg}{ }^{-1}$; (b) the corresponding ex-situ XRD patterns with the standard XRD patterns of $\mathrm{Na}_{2} \mathrm{~S}$ and $\mathrm{Na}_{2} \mathrm{CO}_{3}$ (inset), and (c) the respective ex-situ Fe $2 p$ XPS spectra of the micro-FeS electrode at the denoted states. 
pattern at D0.01 V in Fig. 3b, all the conspicuous diffraction peaks of FeS crystals in fresh electrode disappear. Except for two peaks from the copper current collector, only two broad diffraction peaks at $27^{\circ}$ and $39.2^{\circ}$ are observed, which can be indexed to $\mathrm{Na}_{2} \mathrm{~S}$ crystals. The peaks of Fe could not be detected, mostly due to either the ultra-small crystal size or the amorphous nature of resultant $\mathrm{Fe}$ nanograins. The ex-situ XRD patterns of the $\mathrm{Na} /$ micro-FeS battery are similar to those of its Li counterpart ${ }^{38}$, indicating an analogous mechanism based on the conversion reaction. The sodium-storage mechanism is more evident via tracking the variations of the $\mathrm{Fe} 2 \mathrm{p}$ peaks during the discharge/ charge process. As shown in the ex-situ XPS spectra (Fig. 3c), the $\mathrm{Fe} 2 \mathrm{p}$ peaks are located at 711.05 and $724.03 \mathrm{eV}$ in fresh electrode, respectively, which originate from FeS (ref. 39). Although the $\mathrm{Fe} 2 \mathrm{p}$ signals are weak when the electrode is further discharged to $0.01 \mathrm{~V}$, the peaks for $\mathrm{Fe}^{0}$ can be observed at 704.8 and $719.7 \mathrm{eV}$ (ref. 40). The peaks at 710.5 and $715.2 \mathrm{eV}$ should probably be ascribed to the intermediate Na-rich phases. This speculation can be further confirmed via the fringes for metallic Fe in the highresolution TEM image for the D0.01 V electrode and the highvalence Fe2p peaks in the XPS spectrum after exposing the D0.01 V electrode to air (Supplementary Fig. 6). Therefore, the initial discharge reaction can be expressed as follows:

$$
\mathrm{FeS}+2 \mathrm{Na}^{+}+2 \mathrm{e}^{-} \rightarrow \mathrm{Na}_{2} \mathrm{~S}+\mathrm{Fe}
$$

During the following charge process, an obvious platform arises from $1.25 \mathrm{~V}$, which is probably due to the reversible desodiation reaction to $\mathrm{Na}_{2} \mathrm{FeS}_{2}$ (ref. 41). With charging up to $2.3 \mathrm{~V}$, the initial high charge capacity of $\sim 539 \mathrm{~mA} \mathrm{~h} \mathrm{~g}^{-9}$ is reached, which corresponds to $1.77 \mathrm{Na}$ ions removed, and the charge product is $\mathrm{Na}_{x} \mathrm{FeS}(x=0.23)$. In the XRD pattern where the electrode is charged back to $2.3 \mathrm{~V}$, only one diffraction peak appears at $48.3^{\circ}$ and no peak from FeS is detected. To index the diffraction peak, the powder was exposed to air overnight $(\mathrm{C} 2.3 \mathrm{~V}$ air). It is interesting that the diffraction peak at $48.3^{\circ}$ becomes more intense and two more peaks are resolved at $27.8^{\circ}$ and $30.4^{\circ}$, which all are well indexed to $\mathrm{Na}_{2} \mathrm{CO}_{3}$. This is further confirmed by the ex-situ XPS spectrum of C1s (Supplementary Fig. 7), in which the $\mathrm{C} 1$ s peak from the $\mathrm{O}-\mathrm{C}=\mathrm{O}$ group becomes more intense for the $\mathrm{C} 2.3 \mathrm{~V}$ electrode. The $\mathrm{Fe} 2 \mathrm{p}$ peaks of $\mathrm{Fe}^{2+}$ are clear in the spectrum for the $\mathrm{C} 2.3 \mathrm{~V}$ electrode (Fig. 3c), which results from the desodiation product of $\mathrm{Na}_{2} \mathrm{FeS}_{2}$. The Fe2p peaks at 709.6 and $718.8 \mathrm{eV}$ are mostly due to $\mathrm{Fe}^{2-x}$ of the $\mathrm{Na}_{x} \mathrm{FeS}_{2}$. Therefore, the possible reactions during the reversible desodiation/sodiation processes are listed as follows:

$$
\begin{gathered}
2 \mathrm{Na}_{2} \mathrm{~S}+\mathrm{Fe} \leftrightarrow \mathrm{Na}_{2} \mathrm{FeS}_{2}+2 \mathrm{Na}^{+}+2 \mathrm{e}^{-} \\
\mathrm{Na}_{2} \mathrm{FeS}_{2} \leftrightarrow \mathrm{Na}_{\mathrm{x}} \mathrm{FeS}_{2}+(2-x) \mathrm{Na}^{+}+(2-x) \mathrm{e}^{-}
\end{gathered}
$$

Electrochemical properties of $\mathrm{Na} / \mathrm{FeS}$ battery. The electrochemical performances of both the micro-FeS particles and the yolk-shell FeS@C nanospheres are compared in Fig. 4. Figure 4a,b presents cyclic voltammograms (CVs) of the micro-FeS particles and the yolk-shell FeS@C nanospheres collected at the scan rate of $0.5 \mathrm{mV} \mathrm{s}^{-1}$ for ten cylces. During the initial cathodic scan, a large peak at $\sim 0.6 \mathrm{~V}$ appears for the micro-FeS particles and two pronounced peaks at $\sim 0.45$ and $0.59 \mathrm{~V}$ occur for the yolk-shell FeS@C nanospheres, which is similar to what is observed in the CV curves of the core-shell FeS/C nanospheres (Supplementary Fig. 8). Even though the peaks are slightly different due to the nanostructure and the introduction of the carbon confinement shells in core-shell FeS/C and yolk-shell FeS@C, the reactions are probably related to the conversion from $\mathrm{FeS}$ to $\mathrm{Fe}$ and $\mathrm{Na}_{2} \mathrm{~S}$, and the formation of SEI layers on the surface of the FeS and/or C, in agreement with their charge/discharge profiles (Supplementary Fig. 9). For the anodic scan, a sharp peak at $\sim 1.45 \mathrm{~V}$ and a broad one at $\sim 1.8 \mathrm{~V}$ in both samples correspond to the desodiation
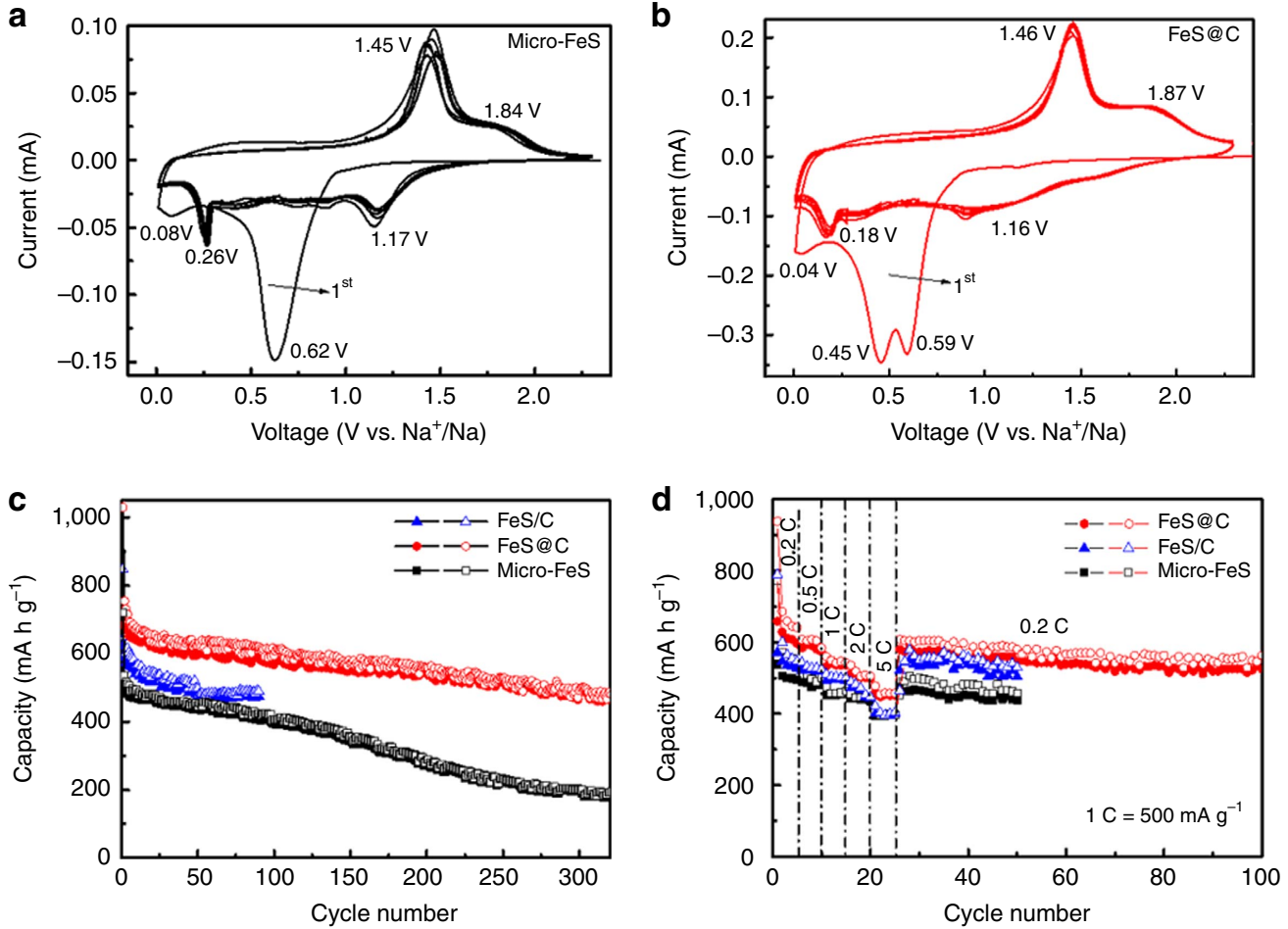

Figure 4 | Electrochemical performance of all the samples. Cyclic voltammograms of (a) the micro-FeS and (b) yolk-shell FeS@C nanospheres at the scan rate of $0.5 \mathrm{mVs}^{-1} ;(\mathbf{c})$ cycling performances at $0.2 \mathrm{C}\left(100 \mathrm{mAg}^{-1}\right)$; and $(\mathbf{d})$ rate capability at various current rates of the micro-FeS, core-shell FeS/C nanospheres and yolk-shell FeS@C nanospheres. 
reaction, where $\mathrm{Na}_{2} \mathrm{FeS}_{2}$ and $\mathrm{Na}_{x} \mathrm{FeS}$ species are probably formed, respectively. Similarly, higher anodic potential peaks of $\mathrm{Li}_{2} \mathrm{FeS}_{2}$ and $\mathrm{Li}_{x} \mathrm{FeS}$ have been reported to occur at $\sim 1.9$ and $2.3 \mathrm{~V}$ in $\mathrm{LIBs}^{42}$. For the subsequent cycles, two pairs of cathodic/anodic peaks occur for both electrodes, consistent with the reaction mechanism proposed above. Furthermore, the CV curves of the $\mathrm{Na} / \mathrm{FeS} @ \mathrm{C}$ cell show great repetition, indicating its better cycling stability and long lifespan. The cycling performances of the cells based on micro-FeS particles, core-shell FeS/C nanospheres and yolk-shell FeS@C nanospheres are plotted in Fig. 4c. It is manifest that the yolk-shell FeS@C nanospheres outperform the micro-FeS particles and the core-shell FeS/C nanospheres, in terms of both capacity and stability. The micro-FeS delivers a decent electrochemical performance with a stable capacity of $\sim 400 \mathrm{~mA} \mathrm{~h} \mathrm{~g}^{-1}$ over 150 cycles. It benefits from the generation of $\mathrm{Fe}$ nanograins by the above-discussed conversion reaction, which results in high conductivity of the electrode. Only a low reversible capacity of $195 \mathrm{mAhg}^{-1}$, however, is retained after 300 cycles, which corresponds to a capacity retention of $37.8 \%$. The rapid capacity decay after 150 cycles is due to the possible pulverization of active materials, cracking of the electrode surface and even electrode materials peeling off from $\mathrm{Cu}$ current collector during prolonged cycling, which can be affirmed by the corresponding SEM images of micro-FeS electrode after cycling (Supplementary Fig. 10). The core-shell FeS/C nanoparticle electrodes possess higher conductivity and shorter sodium ion diffusion paths due to the synergy between the carbon and nanosize effect, thus resulting in a higher utilization and a larger reaction rate of the active materials, and delivering enhanced capacity (620 and $848 \mathrm{~mA} \mathrm{~h} \mathrm{~g}^{-1}$ at the first cycle). Nevertheless, its cycling trend is similar to that of the micro-FeS with comparable reversible capacity of $480 \mathrm{~mA} \mathrm{~h}^{-1}$ after 50 cycles. This indicates that the core-shell structure cannot tolerate the volume expansion of the FeS cores and is easy to rupture. In contrast, when extra voids are created between the FeS nanoparticles and C shells, the yolk-shell FeS@C nanostructure is expected to effectively optimize the electrochemical performance of FeS. The yolk-shell FeS@C nanospheres deliver high initial charge and discharge capacity $(722$ and $1,029 \mathrm{~mA} \mathrm{~h}^{-1}$ ); the reversible capacity higher than the theoretical value is mostly ascribed to the reversible SEI formation and stabilization during the initial cycles. The low Coulombic efficiency $(\sim 70.2 \%)$ is ascribed to the irreversible reactions and electrolyte decomposition. A decent capacity of $488 \mathrm{~mA} \mathrm{~h}^{-1}$ is obtained after 300 cycles, representing a high capacity retention of $67.6 \%$. Along with prolonged cycling, the SEI film layer would become thicker and thicker due to partial reversibility of its formation and stabilization; the yolk-shell structure is prone to be gradually damaged, resulting from the large volume variations of FeS yolk during sodiation/desodiation processes. Therefore, the active materials may lose intact contact from substrate and/or interparticle with increased resistance. All these degenerations lead to the gradual capacity decay of the yolkshell FeS@C electrode. Their rate capabilities were further investigated at various current densities ranging from 0.2 to $5 \mathrm{C}$ (Fig. 4d). It is noteworthy that the micro-FeS and core-shell nano-FeS show comparable low capacity at the high current rate (2 and 5C). It indicates that the core-shell structure cannot endure repeated charge/discharge processes, thereby leading to the serious rupture of the structure and subsequent agglomeration of $\mathrm{FeS}$ nanoparticles after the initial cycles at the low current rates $(0.2,0.5$ and $1 \mathrm{C})$. The yolk-shell FeS@C shows the most remarkable rate capability. An average reversible capacity of $621 \mathrm{mAhg}^{-1}$ is obtained at $0.2 \mathrm{C}$. When the current rate increases to $0.5,1,2$ and $5 \mathrm{C}$, the recorded capacities reach 584,537, 505 and $452 \mathrm{~mA} \mathrm{hg}^{-1}$, respectively.
It should be noted that the capacity retention of FeS@C remains as high as $60 \%$ when the current rate is increased by 25 times. When the rate is directly reduced to $0.2 \mathrm{C}$ again, the capacity recovers to $584 \mathrm{~mA} \mathrm{~h} \mathrm{~g}^{-1}$ and remains stable for 100 cycles. This stable trend is in good agreement with its cycling stability, as shown in Fig. 4c. Furthermore, when a fast charge/discharge test $\left(2 \mathrm{C}=1,000 \mathrm{~mA} \mathrm{~g}^{-1}\right)$ is directly applied, the core-shell FeS/C and yolk-shell FeS@C nanospheres deliver much higher reversible capacity than the microsized FeS over 500 cycles, verifying that the shortened sodium diffusion length and high conductivity is favourable to high-rate reactions (Supplementary Fig. 11). Meanwhile, unlike the significant capacity decay of the micro$\mathrm{FeS}$ and core-shell $\mathrm{FeS} / \mathrm{C}$ after 150 cycles, it is noticed that the yolk-shell FeS@C nanospheres show preferable cycling stability over prolonged cycles, confirming the superiority of the nanostructured yolk-shell architecture. After the rate capability testing, electrochemical impedance spectroscopy measurements on the cells were conducted (Supplementary Fig. 12). Significantly, the FeS@C after 100 cycles still possesses a lower charge transfer resistance $\left(R_{\mathrm{ct}}\right)$ than the micro-FeS after 50 cycles of rate capability testing, implying that there is a favourable SEI film on the FeS@C electrode. The superior electrochemical properties of FeS cathode, therefore, could be gradually achieved via a nanostructuring strategy with respect to nanosized singlecrystalline FeS yolks, carbon shells and crucial void space.

\section{Discussion}

The superiority of the $\mathrm{Na} / \mathrm{FeS}$ battery is further highlighted by its energy density (Fig. 5a). The commercially available $\mathrm{LiFePO}_{4}$ cathode in LIBs is displayed as a reference standard, which can achieve a high energy density of $\sim 530 \mathrm{Wh} \mathrm{kg}^{-1}$. It is obvious that the energy densities of most NIB cathodes and of the RT-Na/S battery are $<300 \mathrm{Wh} \mathrm{kg}^{-1}$. Surprisingly, by integrating the area underneath the discharge curve in Supplementary Fig. 13, the $\mathrm{Na} /$ FeS system in this work stands out among all those energy-storage technologies, as it retains a capacity of $\sim 545 \mathrm{~mA} \mathrm{~h} \mathrm{~g}^{-1}$ over 100 cycles, reaching an energy density as high as $\sim 438 \mathrm{Wh} \mathrm{kg}^{-1}$, exceeding those of other sodium-based batteries. Furthermore, the morphological and compositional changes in the uniform yolkshell FeS@C nanosphere-based electrode after 50 cycles were investigated via SEM and TEM. Theoretically, the volume changes of FeS during sodiation/desodiation processes are estimated according to the following reaction:

$$
\mathrm{FeS}+2 \mathrm{Na} \rightarrow \mathrm{Na}_{2} \mathrm{~S}+\mathrm{Fe}
$$

Assuming $1 \mathrm{~mol}$ of FeS reaction, the volume of $\mathrm{FeS}, \mathrm{Na}_{2} \mathrm{~S}$ and $\mathrm{Fe}$ can be calculated to be $V_{\mathrm{FeS}}=M_{\mathrm{FeS}} / \rho_{\mathrm{FeS}}=18.16 \mathrm{~cm}^{3}, V_{\mathrm{Fe}}=7.1$ $\mathrm{cm}^{3}$ and $V_{\mathrm{Na} 2 \mathrm{~S}}=41.96 \mathrm{~cm}^{3}$, respectively. The volume variation is calculated to be $\sim 170 \%$; thus, the void space is required to be $\sim 16.5 \mathrm{~nm}$ to accommodate the volume expansion of the FeS yolk $(\sim 170 \mathrm{~nm})$. The designed extra void space $(\sim 20 \mathrm{~nm})$, therefore, is supposed to be necessary and sufficient to tolerate the volume changes in the FeS yolk. As revealed in Fig. 5b, the electrode retains the particle structure of fresh FeS@C nanospheres, although it is more like the core-shell structure, mostly because the pulverized and amorphous active materials would occupy the void space due to the conversion reaction. The scanning TEM image (Fig. 5c) shows an obvious core-shell structure; all the void spaces are occupied by the swollen FeS yolk. In agreement with our expectations, these results clearly indicate that the void spaces $(\sim 20 \mathrm{~nm}$ and 1.88 times larger than the volume of the yolk FeS crystal) are large enough to accommodate the volume expansion of FeS particles during the charge/discharge process. As shown in the scanning TEM images (Fig. 5c,d), the energy-dispersive spectroscopy spectrum shows intense signals of the elements $\mathrm{Fe}, \mathrm{S}, \mathrm{Na}, \mathrm{C}$ and $\mathrm{O}$, although the corresponding SAED (inset) rings could only 



b

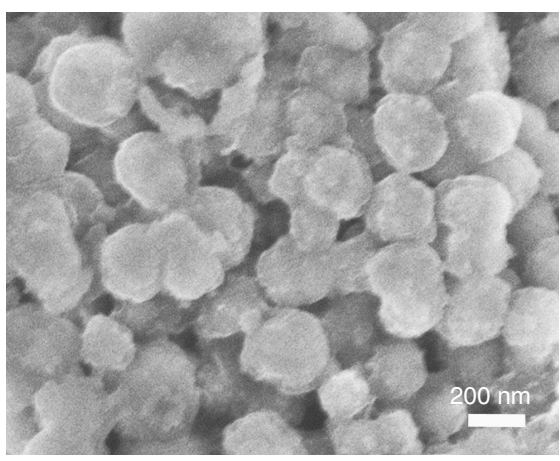

d

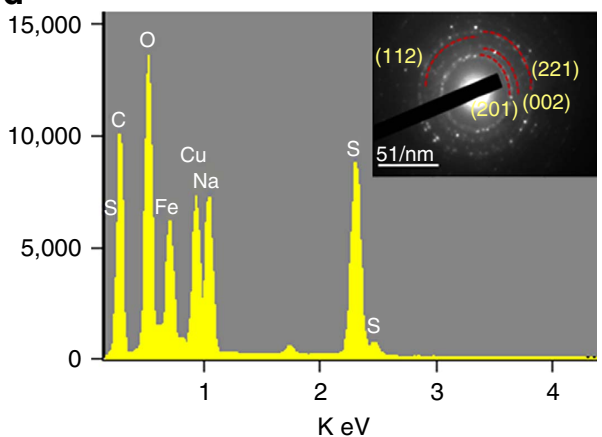

Figure 5 | Superior energy density and morphological changes of the Na-FeS@C cells. (a) Average voltage and energy density versus gravimetric capacity of sodium-storage technologies $\left(\mathrm{LiFePO}_{4}\right.$ plotted for reference). (b) SEM image, (c) scanning TEM image and (d) corresponding energy-dispersive spectroscopy spectrum and SAED pattern (inset) of the yolk-shell FeS@C electrode after 50 cycles at the current rate of 0.2 C.

be indexed to the (201), (002), (112) and (211) plane of crystalline $\mathrm{Na}_{2} \mathrm{CO}_{3}$. This implies that the products of the $\mathrm{Na} / \mathrm{FeS}$ cell via the conversion reaction are amorphous or ultra-fine and only the $\mathrm{Na}_{2} \mathrm{CO}_{3}$ formed during SEI formation is detectable. In comparison, serious electrode cracking is observed for both the micro-FeS electrode and the core-shell FeS/C electrode. The FeS particles in the micro-FeS electrode are wholly destroyed and the electrode shows significant structural cracking and pulverization (Supplementary Fig. 14). The core-shell structure is serious degenerated as well; fractures of the carbon shells and agglomerated FeS cores can be easily observed (Supplementary Fig. 15), resulting in the above inferior Na-storage properties. Owing to the unique yolk-shell structure, the free and accessible voids of the FeS@C nanocomposite spheres are large enough and can tolerate the large volume changes of the FeS core and maintain its original morphology. The carbon shells can improve the conductivity and help to form a stable SEI layer. The unique yolk-shell Na/FeS@C composite cell, therefore, is capable of achieving excellent cycling stability and rate capability.

Furthermore, based on this spatially confined sulfuration strategy, it can be demonstrated that the key factors for successfully constructing unique yolk-shell metal sulfide@C include high quality of the yolk-shell metal oxide@C precursor, the porosity of the carbon shells and sufficient void space between the yolk and shell to accommodate the resultant sulfur. On the other hand, the solid-state reaction temperature is vital for forming the target product. For instance, in this work, different morphologies of $\mathrm{FeS}_{2}$ would be formed from the solid-state reaction of the $\mathrm{Fe}_{3} \mathrm{O}_{4}$ nanospheres with the impregnated sulfur at $350{ }^{\circ} \mathrm{C}$ and $450{ }^{\circ} \mathrm{C}$ instead of $\mathrm{FeS}$ crystals at $550^{\circ} \mathrm{C}$ (Supplementary Fig. 16). We hope that we have also presented a general method for the fabrication of yolk-shell metal sulfide@C nanocomposite via the spatially confined sulfuration strategy, which is expected to be widely extended to a broad class of metal sulfides such as $\mathrm{SnS}_{x}, \mathrm{MoS}_{x}, \mathrm{WS}_{x}$ and $\operatorname{CoS}_{x}$.

\section{Methods}

Synthesis of $\mathbf{F e}_{\mathbf{3}} \mathbf{O}_{\mathbf{4}}$ nanospheres. The $\mathrm{Fe}_{3} \mathrm{O}_{4}$ nanospheres were synthesized through a solvothermal method using trisodium citrate as the stabilizer and $\mathrm{FeCl}_{3}$ as the iron source in ethylene glycol solution. Specifically, $3.25 \mathrm{~g} \mathrm{FeCl}_{3} 6 \mathrm{H}_{2} \mathrm{O}, 1.3 \mathrm{~g}$ trisodium citrate and $1.0 \mathrm{ml} \mathrm{H} \mathrm{H}_{2} \mathrm{O}$ were dissolved in $100 \mathrm{ml}$ ethylene glycol by stirring for $1 \mathrm{~h} ; 6.0 \mathrm{~g}$ sodium acetate $(\mathrm{NaAc})$ was then added into the solution. After magnetic stirring for $1 \mathrm{~h}$ and ultrasonication for $0.5 \mathrm{~h}$, the obtained yellow solution was then sealed in a Teflon-lined autoclave. The autoclave was heated at $200^{\circ} \mathrm{C}$ for $10 \mathrm{~h}$ and then naturally cooled down to room temperature. The $\mathrm{Fe}_{3} \mathrm{O}_{4}$ nanospheres were collected by a magnet and then washed three times with deionized water and ethanol.

Synthesis of $\mathbf{F e}_{\mathbf{3}} \mathbf{O}_{\mathbf{4}} @ \mathrm{SiO}_{\mathbf{2}}$ nanospheres. $\mathrm{Fe}_{3} \mathrm{O}_{4}(0.15 \mathrm{~g})$ nanoparticles obtained above was well dispersed in $194 \mathrm{ml}$ isopropyl alcohol after $0.5 \mathrm{~h}$ ultrasonication and $0.5 \mathrm{~h}$ stirring, followed by adding $18 \mathrm{ml} \mathrm{H}_{2} \mathrm{O}, 10 \mathrm{ml} \mathrm{NH}_{4} \mathrm{OH}$ and $0.2 \mathrm{ml}$ tetraethyl orthosilicate to the flask. The dispersion was further stirred for $2 \mathrm{~h}$ at $40^{\circ} \mathrm{C}$. The core-shell $\mathrm{Fe}_{3} \mathrm{O}_{4} @ \mathrm{SiO}_{2}$ nanospheres were collected by a magnet and then washed three times with deionized water and ethanol.

Synthesis of $\mathbf{F e}_{\mathbf{3}} \mathbf{O}_{\mathbf{4}} @ \mathbf{C}$ nanospheres. An aqueous dispersion containing $0.15 \mathrm{~g}$ $\mathrm{Fe}_{3} \mathrm{O}_{4} @ \mathrm{SiO}_{2}$ particles, $0.46 \mathrm{~g}$ cetyltrimethylammonium bromide and $14.08 \mathrm{ml} \mathrm{H}_{2} \mathrm{O}$ was transferred into a three-neck round-bottom flask. After $0.5 \mathrm{~h}$ ultrasonication and $1 \mathrm{~h}$ stirring, $0.7 \mathrm{~g}$ resorcinol, $56.4 \mathrm{ml}$ absolute ethanol and $0.2 \mathrm{ml} \mathrm{NH}_{4} \mathrm{OH}$ were added sequentially. The flask was stirred for $0.5 \mathrm{~h}$ at $35^{\circ} \mathrm{C}$ and then $0.1 \mathrm{ml}$ formalin (F) was finally added. After continually stirring for $6 \mathrm{~h}$ and polymerization via ageing overnight, the obtained $\mathrm{Fe}_{3} \mathrm{O}_{4} @ \mathrm{SiO}_{2} @ \mathrm{RF}$ nanospheres were collected by a magnet and washed three times with deionized water and alcohol. The core-shell $\mathrm{Fe}_{3} \mathrm{O}_{4} @ \mathrm{SiO}_{2} @ \mathrm{C}$ was prepared by calcination of the $\mathrm{Fe}_{3} \mathrm{O}_{4} @ \mathrm{SiO}_{2} @ \mathrm{RF}$ powder at $600^{\circ} \mathrm{C}$ for $3 \mathrm{~h}$ in $\mathrm{N}_{2}$ atmosphere. Finally, the silica layer was etched away by a $1.0 \mathrm{M}$ $\mathrm{NaOH}$ solution, to yield the yolk-shell $\mathrm{Fe}_{3} \mathrm{O}_{4} @ \mathrm{C}$ nanospheres. 


\section{Synthesis of yolk-shell and core-shell FeS-C nanospheres and micro-FeS.}

A mixture of $\mathrm{Fe}_{3} \mathrm{O}_{4} @$ C:sulfur in weight ratio of 1:1.1 was first ground by mortar and pestle, and then sealed in a Teflon-lined autoclave. The $\mathrm{Fe}_{3} \mathrm{O}_{4}-\mathrm{S} @ \mathrm{C}$ composite was obtained after the autoclave was heated at $155^{\circ} \mathrm{C}$ for $12 \mathrm{~h}$ under air atmosphere. Then, the $\mathrm{Fe}_{3} \mathrm{O}_{4}$-S@C composite was sealed in a stainless steel tube. Finally, the yolk-shell FeS@C nanospheres (FeS@C) were fabricated via heat treatment in the stainless steel tube at $550^{\circ} \mathrm{C}$ for $2 \mathrm{~h}$ in $\mathrm{N}_{2}$ atmosphere. For comparison, the micro-FeS and core-shell FeS/C nanospheres $(\mathrm{FeS} / \mathrm{C})$ were synthesized by the same procedures with core-shell $\mathrm{Fe}_{3} \mathrm{O}_{4} / \mathrm{C}$ or $\mathrm{Fe}_{3} \mathrm{O}_{4}$ nanoparticles with $\mathrm{S}$ as starting materials, respectively.

Structural characterization. The morphologies of the samples were investigated by field-emission SEM (JEOL JSM-7500FA) and TEM (JEOL 2011, $200 \mathrm{keV}$ ). Raman spectra were collected by a $10-\mathrm{mW}$ helium/neon laser at $632.8 \mathrm{~nm}$ excitation, which was filtered by a neutral density filter to reduce the laser intensity and a CCD (charge-coupled detector). The XRD patterns were collected by powder XRD (GBC MMA diffractometer) with $\mathrm{Cu} \mathrm{K} \alpha$ radiation at a scan rate of 2 and 0.5 degree per minute. The XPS experiments were carried out using $\mathrm{Al} \mathrm{K} \alpha$ radiation and fixed analyser transmission mode. The pass energy was $60 \mathrm{eV}$ for the survey spectra and $20 \mathrm{eV}$ for the specific elements. The XPS samples were stored in an argon-filled glove box before testing to avoid oxidation.

Electrochemical measurements. The electrochemical tests were conducted by assembling coin-type half-cells in an argon-filled glove box. The electrode slurry was prepared by fully mixing $80 \mathrm{wt} \%$ active materials (M-FeS, core-shell $\mathrm{FeS} / \mathrm{C}$ or yolk-shell FeS@C), 10 wt\% carbon black and 10 wt\% carboxymethyl cellulose in an appropriate amount of water by planetary mixer (KK-250S). Then, the obtained slurry was pasted on copper foil using a doctor blade with a thickness of $100 \mu \mathrm{m}$, which was followed by drying at $80^{\circ} \mathrm{C}$ in a vacuum oven overnight. The working electrode was prepared by punching the electrode film into discs $0.97 \mathrm{~cm}$ in diameter; the loading amounts of active materials on each electrode disc were $\sim 1.5$ $2.0 \mathrm{mg} \mathrm{cm}^{-2}$. The sodium foil was cut using a surgical blade from sodium bulk stored in mineral oil. The sodium foil was employed as both reference and counter electrode. The electrodes were separated by a glass fibre separator. Electrolyte consisting of $1.0 \mathrm{M} \mathrm{NaClO}_{4}$ in propylene carbonate/ethylene carbonate with a volume ratio of $1: 1$ and $5 \mathrm{wt} \%$ fluoroethylene carbonate additive (PC/EC $+5 \mathrm{wt} \%$ FEC) was prepared and used in this work. The electrochemical performances were tested on a LAND Battery Tester within a voltage window of $0.01-2.3 \mathrm{~V}$. All the capacities of cells have been normalized based on the weight of active materials in the form of FeS for the micro-FeS, and FeS-C nanocomposite for the core-shell FeS/C and the yolk-shell FeS@C. Cyclic voltammetry was performed using a Biologic VMP-3 electrochemical workstation.

\section{References}

1. Tarascon, J.-M. \& Armand, M. Issues and challenges facing rechargeable lithium batteries. Nature 414, 359-367 (2001).

2. Goodenough, J. B. \& Park, K.-S. The Li-ion rechargeable battery: a perspective. J. Am. Chem. Soc. 135, 1167-1176 (2013).

3. Vogt, L. O. et al. Understanding the interaction of the carbonates and binder in Na-ion batteries: a combined bulk and surface study. Chem. Mater. 27, 1210-1216 (2015)

4. Kim, S. W., Seo, D. H., Ma, X., Ceder, G. \& Kang, K. Electrode materials for rechargeable sodium-ion batteries: potential alternatives to current lithium-ion batteries. Adv. Energy Mater. 2, 710-721 (2012).

5. Palomares, V., Casas-Cabanas, M., Castillo-Martinez, E., Han, M. H. \& Rojo, T. Update on Na-based battery materials. A growing research path. Energy Environ. Sci. 6, 2312-2337 (2013).

6. Paulsen, J. M., Thomas, C. L. \& Dahn, J. R. $\mathrm{O}_{2}$ structure $\mathrm{Li}_{2 / 3} \mathrm{Ni}_{1 / 3} \mathrm{Mn}_{2 / 3} \mathrm{O}_{2}$ : a new layered cathode material for rechargeable lithium batteries I. Electrochemical properties. J. Electrochem. Soc. 147, 861-868 (2000).

7. Tripathi, R., Ramesh, T. N., Ellis, B. L. \& Nazar, L. F. Scalable synthesis of tavorite $\mathrm{LiFeSO}_{4} \mathrm{~F}$ and $\mathrm{NaFeSO}_{4} \mathrm{~F}$ cathode materials. Angew. Chem. Int. Ed. 49, 8738-8742 (2010).

8. Moreau, P., Guyomard, D., Gaubicher, J. \& Boucher, F. Structure and stability of sodium intercalated phases in olivine $\mathrm{FePO}_{4}$. Chem. Mater. 22, 4126-4128 (2010)

9. Cao, Y. L. et al. Reversible sodium ion insertion in single crystalline manganese oxide nanowires with long cycle life. Adv. Mater. 23, 3155-3160 (2011).

10. Sathiya, M., Hemalatha, K., Ramesha, K., Tarascon, J. M. \& Prakash, A. S. Synthesis, structure, and electrochemical properties of the layered sodium insertion cathode material: $\mathrm{NaNi}_{1 / 3} \mathrm{Mn}_{1 / 3} \mathrm{Co}_{1 / 3} \mathrm{O}_{2}$. Chem. Mater. 24, 1846-1853 (2012).

11. Yabuuchi, N. et al. $\mathrm{P} 2$-type $\mathrm{Na}_{\mathrm{x}}\left[\mathrm{Fe}_{1 / 2} \mathrm{Mn}_{1 / 2}\right] \mathrm{O}_{2}$ made from earth-abundant elements for rechargeable Na batteries. Nat. Mater. 11, 512-517 (2012).

12. Wang, L. et al. A superior low-cost cathode for a Na-ion battery. Angew. Chem. Int. Ed. 52, 1964-1967 (2013).
13. Sun, Y. et al. Direct atomic-scale confirmation of three-phase storage mechanism in $\mathrm{Li}_{4} \mathrm{Ti}_{5} \mathrm{O}_{12}$ anodes for room-temperature sodium-ion batteries. Nat. Commun. 4, 1870 (2013).

14. Li, S. et al. Effect of carbon matrix dimensions on the electrochemical properties of $\mathrm{Na}_{3} \mathrm{~V}_{2}\left(\mathrm{PO}_{4}\right)_{3}$ nanograins for high-performance symmetric sodium-ion batteries. Adv. Mater. 26, 3545-3553 (2014).

15. Cao, Y. L. et al. Sodium ion insertion in hollow carbon nanowires for battery applications. Nano Lett. 12, 3783-3787 (2012).

16. Qian, J. F. et al. High capacity Na-storage and superior cyclability of nanocomposite $\mathrm{Sb} / \mathrm{C}$ anode for $\mathrm{Na}$-ion batteries. Chem. Commun. 48, 7070-7072 (2012).

17. Xu, Y. H., Zhu, Y. J., Liu, Y. H. \& Wang, C. S. Electrochemical performance of porous carbon/tin composite anodes for sodium-ion and lithium-ion batteries. Adv. Energy Mater. 3, 128-133 (2013).

18. Wang, Y. X., Chou, S. L., Liu, H. K. \& Dou, S. X. Reduced graphene oxide with superior cycling stability and rate capability for sodium storage. Carbon. N. Y. 57, 202-208 (2013).

19. Li, W. J. et al. $\mathrm{Sn}_{4+\mathrm{x}} \mathrm{P}_{3} @$ Amorphous Sn-P composites as anodes for sodiumion batteries with low cost, high capacity, long life, and superior rate capability. Adv. Mater. 26, 4037-4042 (2014).

20. Hartmann, P. et al. A rechargeable room-temperature sodium superoxide $\left(\mathrm{NaO}_{2}\right)$ battery. Nat. Mater. 12, 228-232 (2013).

21. Das, S. K., Xu, S. M. \& Archer, L. A. Carbon dioxide assist for non-aqueous sodium-oxygen batteries. Electrochem. Commun. 27, 59-62 (2013).

22. Wang, J., Yang, J., Nuli, Y. \& Holze, R. Room temperature Na/S batteries with sulfur composite cathode materials. Electrochem. Commun. 9, 31-34 (2007).

23. Hwang, T. H., Jung, D. S., Kim, J. -S., Kim, B. G. \& Choi, J. W. Onedimensional carbon-sulfur composite fibers for $\mathrm{Na}-\mathrm{S}$ rechargeable batteries operating at room temperature. Nano Lett. 13, 4532-4538 (2013).

24. Xin, S., Yin, Y. -X., Guo, Y. -G. \& Wan, L. -J. A high-energy room-temperature sodium-sulfur battery. Adv. Mater. 26, 1261-1265 (2014).

25. Kim, J. et al. The electrochemical properties of sodium/iron sulfide battery using iron sulfide powder coated with nickel. Rev. Adv. Mater. Sci. 28, 107-110 (2011)

26. Kim, T. B. et al. Electrochemical properties of sodium/pyrite battery at room temperature. J. Power Sources 174, 1275-1278 (2007).

27. $\mathrm{Hu}, \mathrm{Z}$. et al. Pyrite $\mathrm{FeS}_{2}$ for high-rate and long-life rechargeable sodium batteries. Energy Environ. Sci. 8, 1309-1316 (2015).

28. Qu, B. H. et al. Layered $\mathrm{SnS}_{2}$-reduced graphene oxide composite-a highcapacity, high-rate, and long-cycle life sodium-ion battery anode material. $A d v$ Mater. 26, 3854-3859 (2014).

29. Wang, Y.-X., Chou, S.-L., Wexler, D., Liu, H.-K. \& Dou, S.-X. Highperformance sodium-ion batteries and sodium-ion pseudocapacitors based on $\mathrm{MoS}_{2}$ /graphene composites. Chem. Eur. J. 20, 9607-9612 (2014).

30. Kim, J.-S. et al. The discharge properties of $\mathrm{Na} / \mathrm{Ni}_{3} \mathrm{~S}_{2}$ cell at ambient temperature. J. Power Sources 178, 852-856 (2008).

31. Klein, F., Jache, B., Bhide, A. \& Adelhelm, P. Conversion reactions for sodiumion batteries. Phys. Chem. Chem. Phys. 15, 15876-15887 (2013).

32. Yu, D. et al. High-capacity antimony sulfide nanoparticle-decorated graphene composite as anode for sodium-ion batteries. Nat. Commun. 4, 2922-2928 (2013).

33. Shen, L. et al. Formation of nickel cobalt sulfide ball-in-ball hollow spheres with enhanced electrochemical pseudocapacitive properties. Nat. Commun. 6, 6694 (2015).

34. He, G. et al. Tailoring porosity in carbon nanospheres for lithium-sulfur battery cathodes. ACS Nano 7, 10920-10930 (2013).

35. Liu, J. et al. A facile soft-template synthesis of mesoporous polymeric and carbonaceous nanospheres. Nat. Commun. 4, 2798 (2013).

36. Golodnitsky, D. \& Peled, E. Pyrite as cathode insertion material in rechargeable lithium/composite polymer electrolyte batteries. Electrochim. Acta 45, 335-350 (1999).

37. Fei, L. et al. Reduced graphene oxide wrapped FeS nanocomposite for lithiumion battery anode with improved performance. ACS Appl. Mater. Interfaces $\mathbf{5}$ 5330-5335 (2013).

38. Zhao, L. et al. Remarkably improved electrode performance of bulk MnS by forming a solid solution with FeS-understanding the Li storage mechanism. Adv. Funct. Mater. 24, 5557-5566 (2014).

39. Dong, C., Zheng, X., Huang, B. \& Lu, M. Enhanced electrochemical performance of FeS coated by Ag as anode for lithium-ion batteries. Appl. Surf. Sci. 265, 114-119 (2013).

40. Mills, P. \& Sullivan, J. A study of the core level electrons in iron and its three oxides by means of X-ray photoelectron spectroscopy. J. Phys. D Appl. Phys. 16, 723-732 (1983).

41. Fong, R., Jones, C. \& Dahn, J. A study of pyrite-based cathodes for ambient temperature lithium batteries by in $s^{1 t u}{ }^{57} \mathrm{Fe}$ Mossbauer spectroscopy. J. Power Sources 26, 333-339 (1989).

42. Wu, B., Song, H., Zhou, J. \& Chen, X. Iron sulfide-embedded carbon microsphere anode material with high-rate performance for lithium-ion batteries. Chem. Commun. 47, 8653-8655 (2011) 


\section{Acknowledgements}

This work is financially supported by Australian Research Council (ARC) through a Linkage Project (LP120200432 and DP140104062), the Commonwealth of Australia through the Automotive Australia 2020 Cooperative Research Centre (Auto CRC), the National Natural Science Foundation (NSF) of China (21210004) and the Shanghai Sci. \& Tech. Committee (14JC1400700). We acknowledge the use of the facilities at the UOW Electron Microscopy Centre funded by ARC grants (LE0882813 and LE0237478). We thank Dr Tania Silver for critical reading of the manuscript.

\section{Author contributions}

Y.X.W. and J.P.Y. made equal contribution to the paper. Y.X.W., J.P.Y. and S.L.C. conceived this work. J.P.Y. synthesized the $\mathrm{Fe}_{3} \mathrm{O}_{4}$ and yolk-shell $\mathrm{Fe}_{3} \mathrm{O}_{4}$ precursor. Y.X.W. designed and carried out the electrochemical experiments. Y.X.W., J.P.Y. and S.L.C. wrote the paper. H.K.L., W.X.Z., D.Y.Z. and S.X.D. supervised the project. All the authors participated in analysis and discussions of the results and in preparing the manuscript.

\section{Additional information}

Supplementary Information accompanies this paper at http://www.nature.com/ naturecommunications

Competing financial interests: The authors declare no competing financial interests.

Reprints and permission information is available online at http://npg.nature.com/ reprintsandpermissions/

How to cite this article: Wang, Y.-X. et al. Uniform yolk-shell iron sulfide-carbon nanospheres for superior sodium-iron sulfide batteries. Nat. Commun. 6:8689 doi: 10.1038/ncomms9689 (2015).

\section{(c) (i)}

This work is licensed under a Creative Commons Attribution 4.0 International License. The images or other third party material in this article are included in the article's Creative Commons license, unless indicated otherwise in the credit line; if the material is not included under the Creative Commons license, users will need to obtain permission from the license holder to reproduce the material. To view a copy of this license, visit http://creativecommons.org/licenses/by/4.0/ 